\title{
NovCare 2013 (Novel methods for subsurface characterization and monitoring: from theory to practice)
}

\author{
U. Sauer · P. Dietrich
}

Received: 26 May 2014/ Accepted: 13 June 2014/Published online: 4 July 2014

(C) Springer-Verlag Berlin Heidelberg 2014

As safe and effective use of the subsurface environment is a major challenge facing our society, there is a great need to improve our understanding of the subsurface and to observe and investigate natural and anthropogenically influenced systems. Characterization of the subsurface includes the investigation of both groundwater and subsurface soils and their interaction processes. The range of monitoring tools used can be extended to include remote sensing tools [e.g., Fourier transform infrared spectroscopy (FTIR)], applicable at the near-surface to estimate gas-soil gas exchange processes. One example that highlights the importance of subsurface characterization and monitoring is the detection of groundwater contamination, to provide data for developing plans to prevent any further contamination and remediate existing contamination. With an increasing demand for investigation methods that have both high accuracy and resolution across a variety of spatial scales, there are several challenges for monitoring and exploration technologies in environmental research. These challenges include, among others, the identification and parameterization of system relevant physical, chemical, biological processes, as well as the determination of interactions between different scales. These challenges require high-resolution methods or novel data processing and common interpretation of data measured by different methods. In particular, cost-effective methods that are minimally destructive and can be rapidly applied are taken into consideration. Methods for subsurface characterization include e.g., geophysical, hydrogeological and direct push

U. Sauer $(\bowtie) \cdot$ P. Dietrich

Department of Monitoring and Exploration Technologies,

UFZ-Helmholtz Centre for Environmental Research,

Permoserstrasse 15, 04318 Leipzig, Germany

e-mail: uta.sauer@ufz.de
(DP) technologies, borehole-based, and tomographic methods.

The NovCare conference (Novel methods for subsurface characterization and monitoring: from theory to practiceestablished in 2009) provides a platform to present and discuss state of the art developments and concepts. Existing methods are often refined and new methods are continually being developed. Therefore, this symposium presents recent developments, examples of field applications and introduces method concepts such as direct push, geophysical methods, adaptive (sensor) networks, and novel monitoring sensors. It also highlights the application of these methods in different thematic areas.

The NovCare 2013 International Conference (Novel methods for subsurface characterization and monitoring: from theory to practice) took place from May 13-16th 2013 at the Helmholtz Centre for Environmental Research in Leipzig. This conference, which was organized by the Helmholtz Centre for Environmental Research, the University of Tuebingen, the Kansas Geological Survey and the Michigan State University, was the third successive annual conference. This conference series, which began in Leipzig in 2009 and then moved to Cape Cod in the US in 2011, has proven to be an excellent forum for exchanging ideas and experiences related to the challenges of subsurface characterization and monitoring. NovCare 2013 again provided a rare opportunity and an outstanding platform for researchers and practitioners from all over the world to exchange their ideas and experiences in dealing with the challenges of subsurface characterization and monitoring using a variety of methods.

The conference had a strong interdisciplinary and international flavor, with around 100 participants from 13 countries taking part. Twelve companies and institutes presented their expertise and novel equipment and 
techniques in the accompanying exhibition and field demonstrations. The seven thematic categories of NovCare 2013 were: (1) soils and unconsolidated deposits, (2) thermal use of the shallow subsurface, (3) stream-aquifer interactions, (4) flow and transport in the saturated and unsaturated zone, (5) geotechnical site characterization, (6) watershed characterization, and (7) long-term monitoring. In total, 46 presentations were given and 19 posters were on display. Seven invited speakers delivered talks of specific relevance to one of the focus areas or discussed topics of general interest. Keynote speakers included: Tom Lunne, Dave Walsh, Philippe Behra, Steffen Birk, Michael Cardiff, Anthony L. Endres, and Michael Gooseff. At NovCare 2013, the organizers identified two important tasks-(1) direct push technology and (2) geothermal use of the shallow subsurface-which were discussed in detail by the participants and important tasks to be considered in future research, were defined.

This thematic issue provides a selection of results of NovCare 2013.

The paper presented by Rogiers et al. (2014) describes the application of hundreds of cone penetration tests (CPT) to derive hydraulic conductivity depth profiles for development of regional aquifer models. The researchers calibrated the geotechnical (CPT) and hydraulic DP data [gained from direct push injection logging (DPIL), hydraulic profiling tool (HPT) and direct push slug test (DPST)] with detailed laboratory and air permeability measurements. At the test site, the hydraulic DP data images clearly show a high K sand layer, while the CPT data calibration does not capture this zone in detail. In the paper, using CPT calibration data for the entire lithostratigraphical column is proposed. The authors state that the derivation of hydrogeological parameters from various DP technologies can improve both conceptual model building as well as the performance of a regional groundwater model. However, there is still some work that needs to be completed e.g., to include realistic dispersion values that are based on DP data.

The Paradis et al. (2014) paper illustrates the potential of combining hydraulic and CPT/SMR (cone penetrometer tests combined with soil moisture and electrical resistivity measurements) data for estimating hydrogeological parameters, such as those associated with groundwater flow and contaminant transport. The authors show that a hydrogeophysical approach to characterize the heterogeneous hydraulic properties of an aquifer is significantly more time efficient compared to conventional hydraulic testing approaches. CPT/SMR data derived via site-specific hydrogeophysical relations appear to contain enough information to infer the hydraulic property heterogeneity, as the interpolation of converted CPT/SMR data into hydraulic information reflects the sedimentary architecture of the studied littoral aquifer, which involves hydrofacies unit interdigitation and spatial trends in hydraulic properties.

The objective of the Birk et al. (2014) paper is to explore thresholds in karst aquifers and how they can be controlled, using the reference example of the Lurbach system (Austria). This karst system is well understood from earlier investigations and has different types of thresholds. In this paper, thresholds in the physicochemical spring response were successfully employed to help identify any change in the functioning of the Lurbach karst system, which possibly occurred due to a threshold related to sediment transport within the karst conduits being crossed. Hence, the analysis of response thresholds in the Lurbach system reveals that a functional threshold was crossed so that the flow and transport behavior within this system was changed over a period of several years. The authors assume that the occurrence of such changes in the functioning of karst systems obviously poses great challenges to the prediction of flow and transport phenomena in this type of setting.

Combinations of various methods are also used to investigate dynamic systems. Novel approaches exist to monitor the spatial and temporal behavior of soil properties. Two examples are described in the paper by Altdorff and Dietrich (2014) and Ma et al. (2014).

Altdorff and Dietrich (2014) describe a procedure to identify areas with different temporal behavior using timelapse electromagnetic induction (EMI) data with different investigation depths. They assume that changes in apparent conductivity are mainly related to changes in soil water content (SWC) and its mineralization. However, the electromagnetic induction method is affected by several survey conditions which hinder a direct comparison of time-lapse data. Therefore, the authors apply a data normalization function, assuming that the majority of shifts of measured data originate from field calibration. Altdorff and Dietrich identify the intensity of spatial changes using the standard deviation (SD) as an indication for the intensity of soil property variability and separate the dynamic signal from the background noise. With this procedure, they were able to identify two moisture systems (a shallow system influenced by varying altitude and a deeper one controlled by geology) in the field data which could not be seen before. The authors state that the EMI time-lapse monitoring method and analysis can be used in landslide investigations, preferably at the beginning of the slope stability study to distinguish between high- and low-risk areas.

In addition to this, the paper by Ma et al. (2014) shows how Electric Resistivity Imaging (ERI) is used to describe the spatiotemporal variability of soil water in relation to vegetation structure and throughfall. In this study, the spatial and temporal dynamics of soil moisture were captured at a mature forest site in Michigan, using weekly ERI measurements augmented with throughfall measurements, 
soil temperature measurements, and a detailed vegetation survey. Results show that throughout the growing season, the soil moisture gradually declined despite strong differences in cumulative monthly rainfall. Based on the resistivity data gathered, the authors observed that, with increasing surface soil water influxes during the growing season, significant spatial heterogeneities in resistivity or soil moisture occurred below ground level. Some of these resistivity patterns showed some correlation with vegetation structure and throughfall data. These findings can help us to characterize the interactions between vegetation and soil moisture to forecast long-term water resources and ecosystem health.

In the context of energy transition, especially in view of securing the base load capacity of alternative energy sources, measuring the subsurface as a thermal and material storage area is becoming more important.

Near-surface geothermal systems for heating and cooling residential and industrial buildings have been established as a good alternative to conventional systems. Applied techniques that are used nowadays include borehole heat exchangers and thermal aquifer energy storage. Despite its capability to reduce $\mathrm{CO}_{2}$ emissions, intense thermal use of the subsurface has predictable negative effects on the environment, such as depletion of groundwater quality resulting in the reduction of groundwater ecosystem services and over-exploitation of the thermal potential-which in turn causes reduced system efficiency. The aspects of geothermal use of the shallow subsurface, the conflicts between energy use and groundwater protection, and challenges and strategies for sustainable use were discussed by the participants at NovCare 2013.

For example, Di Sipio et al. (2014) attempted to determine the properties of subsurface thermal conductivity at a regional scale in Calabria, Italy. Determining the suitability of a local area for the geothermal application of lowenthalpy systems at different scales requires better characterization of the thermal and petrophysical properties of the subsoil. Knowledge of thermal conductivity is a key parameter in modeling the potential of the deep subsurface structure for the exploitation of geothermal energy resources in low, medium, and high enthalpies. A direct thermal measurement performed on representative specimens was carried out to provide real data to planners, public administrations and operators involved in the geothermal sector. The proposed approach of determining thermal conductivity in terms of main geologic formations helps us to avoid assigning thermal property values extrapolated from different geological contexts that are not representative of the real conditions of the study area.

The paper by Lehr and Sass (2014) shows an example of a prospective geothermal array, relevant for project engineering. They presented an installation which used an enhanced thermal response test (eTRT or eGRT) to determine effective thermal conductivity with a spatial resolution of $0.5 \mathrm{~m}$. The high local resolution over the whole profile enables investigators to differentiate between highly conductive sections from convectively influenced heat transfer zones. The investigations proved that using relatively high dimensions for positioning the borehole heat exchanger (BHE) — around $400 \mathrm{~m}$-is thermally beneficial, as the maximum heat extraction which is technically possible would have been significantly less, with final depths of only 200 or $100 \mathrm{~m}$.

One fundamental aspect of European climate change efforts is the use of carbon capture and storage (CCS) technology to minimize greenhouse gas concentration. A monitoring approach applied at different scales is required to reliably detect and assess $\mathrm{CO}_{2}$ leakages from storage formations in the shallow subsurface and the atmosphere. Within this monitoring approach, tools described in the paper of Sandig et al. (2014) and Reiche et al. (2014) can reliably monitor locations of higher gas concentrations in the shallow subsurface and the atmosphere.

Sandig et al. (2014) present results of comprehensive investigations along a $500 \mathrm{~m}$ long profile at the Hartoušov (Czech Republic) natural $\mathrm{CO}_{2}$ degassing site and provide structural information about the subsurface and interaction processes in relation to parameters measured. Measurement of $\mathrm{CO}_{2}$ concentrations and investigation of the subsurface using Electrical Resistivity Tomography (ERT) and self potential (SP) methods provide information about subsurface properties.

The use of remote sensing [open-path Fourier transform infrared (OP-FTIR) spectroscopy] in combination with other measurements (geophysics and DP) enables a joint data interpretation approach. Ground-based optical remote sensing (ORS) techniques have become more widely used for the identification and quantification of fugitive pollutants or greenhouse gases from point sources, as well as spatially extended emissions. Active and passive open-path FTIR spectroscopy is especially suited to the detection of gaseous emissions of chemical agents.

Reiche et al. (2014) present an evaluation of three ORS techniques: passive and active open-path Fourier transform infrared spectroscopy (OP-FTIR) and open-path tunable diode laser absorption spectroscopy (TDLAS). In this paper, the results of a release experiment using acetylene $\left(\mathrm{C}_{2} \mathrm{H}_{2}\right)$ as a tracer gas are presented. The experiment aimed to evaluate the capability and comparability of the three methods to detect the emission source and to quantify release rates. The results reveal that passive OP-FTIR is a valuable tool for the rapid detection and imaging of emission sources and the spatial tracer gas distribution, while with active OP-FTIR and TDLAS, $\mathrm{C}_{2} \mathrm{H}_{2}$ concentrations in the sub-ppm range could be quantified. 
Due to the success of this conference series, a fourth conference (NovCare 2015) will be held in Kansas, and has tentatively been scheduled for May 19-21 2015. The organizers will provide again a platform for presenting and discussing state of the art developments and concepts for subsurface characterization.

The guest authors are very grateful to the authors for their valuable contributions, and for the thorough and constructive engagement of many reviewers who evaluated their submissions. We would like to express our gratitude to coordinator Barbara Kolditz for their assistance and guidance during the preparation of this thematic issue.

\section{References}

Altdorff D, Dietrich P (2014) Delineation of areas with different temporal behavior of soil properties at a landslide affected Alpine hillside using time-lapse electromagnetic data. Environ Earth Sci. doi:10.1007/s12665-014-3240-7

Birk S, Wagner T, Mayaud C (2014) Threshold behavior of karst aquifers: the example of the Lurbach karst system (Austria). Environ Earth Sci. doi:10.1007/s12665-014-3122-z

Di Sipio E, Galgaro A, Destro E, Teza G, Chiesa S, Giaretta A, Manzella A (2014) Subsurface thermal conductivity assessment in Calabria (southern Italy): a regional case study. Environ Earth Sci. doi:10.1007/s12665-014-3277-7

Lehr C, Sass I (2014) Thermo-optical parameter acquisition and characterisation of geologic properties-a 400 meter deep BHE in a Karstic Alpine marble aquifer. Environ Earth Sci. doi:10. 1007/s12665-014-3310-x

Ma Y, Van Dam RL, Jayawickreme DH (2014) Soil moisture variability in a temperate deciduous forest: insights from electrical resistivity and throughfall data. Environ Earth Sci. doi:10.1007/s12665-014-3362-y

Paradis D, Tremblay L, Lefebvre R, Gloaguen E, Rivera A, Parent M, Ballard J-M, Michaud Y, Brunet P (2014) Field characterization and data integration to define the hydraulic heterogeneity of a shallow granular aquifer at a sub-watershed scale. Environ Earth Sci. doi:10.1007/s12665-014-3318-2

Reiche N, Westerkamp T, Lau S, Borsdorf H, Dietrich P, Schütze C (2014) Comparative study to evaluate three ground-based optical remote sensing techniques under field conditions by a gas tracer experiment. Environ Earth Sci. doi:10.1007/s12665-014-3312-8

Rogiers B, Vienken T, Gedeon M, Batelaan O, Mallants D, Huysmans M, Dassargues A (2014) Multi-scale aquifer characterization and groundwater flow model parameterization using direct push technologies. Environ Earth Sci (this issue). doi:10.1007/s12665014-3416-1

Sandig C, Sauer U, Bräuer K, Serfling U, Schütze C (2014) Comparative study of geophysical and soil-gas investigations at the Hartoušov (Czech Republic) natural $\mathrm{CO}_{2}$ degassing site. Environ Earth Sci. doi:10.1007/s12665-014-3242-5 